\title{
La peste y el distanciamiento en El ganso de oro de Lope de Vega Plague and Distancing in Lope de Vega's El ganso de oro
}

\section{Christopher C. Oechler}

https://orcid.org/0000-0002-6526-0220

Gettysburg College

ESTADOS UNIDOS

coechler@gettysburg.edu

[Hipogrifo, (issn: 2328-1308), 8.2, 2020, pp. 703-714]

Recibido: 24-04-2020 / Aceptado: 11-05-2020

DOI: http://dx.doi.org/10.13035/H.2020.08.02.40

Resumen. A pesar de la amenaza generalizada de peste durante el Siglo de Oro, el contagio rara vez se escenificaba en las comedias. El ganso de oro de Lope de Vega sirve como una notable excepción a esa tendencia. En su mezcla de géneros, del pastoril a la comedia palatina con una fuerte dosis de magia, la comedia nos proporciona una aproximación a la vida durante semejante tiempo de pestilencia. La crisis sanitaria actual de la COVID-19 sugiere una nueva lectura de la obra, poco estudiada anteriormente. Este artículo repasa el papel clave de la peste en El ganso de oro para destacar su tema principal: el distanciamiento, entendido a base de manifestaciones físicas, sociales y emocionales.

Palabras clave. Peste; pestilencia; distanciamiento; Parténope.

Abstract. Despite presenting a widespread threat during the Golden Age, the plague was rarely dramatized in comedias. Lope de Vega's El ganso de oro serves as a notable exception to this general trend. With its blending of genres, from the pastoral to the palatial with a strong dose of magic, the play provides insight into life during such a time of pestilence. The current COVID-19 health crisis suggests a new reading of the work, which has previously suffered from a lack of critical attention. This article reviews the key role of the plague in El ganso de oro to highlight its main theme: distancing, understood through its physical, social, and emotional manifestations.

Keywords. Plague; Pestilence; Distancing; Parthenope. 
En el siglo XVı la peste era un mal común. Brotaba en varios lugares y momentos, afectaba e infectaba desde los más pobres hasta los más ricos indiscriminadamente: «es semejante a una bestia muy fiera, que a nadie perdona, sin miedo y sin respecto, destruyendo no solo casas y despoblando ciudades, pero asolando reinos y provincias grandes» ${ }^{1}$. Bartolomé Bennassar afirma que «[l]a peste, en el siglo XVI, es un viejo fantasma con apariciones periódicas que los hombres saben ineluctables, contra las que luchan obstinadamente, pero sin hacerse ilusiones» ${ }^{2}$. Las tasas de muertos evidencian las secuelas que dejó en la población y la economía de la España imperial, cuando la única opción viable parecía ser evitar a todo coste los lugares infectados y a las personas enfermas ${ }^{3}$. La cuarentena era la solución por excelencia, con hospitales señalados como centros de acogida de los pestilentes, aún mejor si aquellos se ubicaban al otro lado de las murallas de la ciudad ${ }^{4}$. Se multiplicaban las listas negras de zonas infectadas, la vigilancia de entradas y salidas de las ciudades, la limpieza a base de vinagre y fuego y, como primer y último recurso, el rezo. Los gobiernos huían del contagio: la Corte de Carlos V abandonó Valladolid en 1527 a causa de la peste ${ }^{5}$, y Felipe III pasó los primeros meses de su reinado desplazándose de un lugar a otro intentando siempre adelantarse a la llegada de la enfermedad ${ }^{6}$.

Bajo esta amenaza omnipresente de infección y muerte, Lope de Vega escribió su comedia El ganso de oro (1588-1595). Su relevancia a día de hoy se encuentra aumentada por la pandemia que ha suscitado la COVID-19, y, en efecto, esta crisis sanitaria actual sugiere una nueva lectura de la obra, poco estudiada anteriormen$t^{7}$. En su mezcla de géneros, del pastoril a la comedia palatina con una fuerte dosis de magia, la comedia nos proporciona una aproximación a la vida durante semejante tiempo de crisis, un asunto que curiosamente ha dejado poca constancia en el teatro del Siglo de $\mathrm{Oro}^{8}$. A continuación, analizaré el papel clave de la peste en El ganso de oro para destacar el tema principal de la obra: el distanciamiento, entendido a base de sus manifestaciones físicas, sociales y emocionales. Lope nos enseña una imagen de la peste que afecta profundamente a todos, no solo a los enfermos, demostrando así el sufrimiento y las rupturas en una sociedad castigada y cicatrizada.

\footnotetext{
1. Freylas, Conocimiento, curación y preservación de la peste, fol. 163v.

2. Bennassar, 2015, p. 188.

3. El número más aceptado es medio millón de difuntos (Pérez Moreda, 1994, p. 46; MacKay, 2019, p. 6).

4. Clouse, 2013, pp. 144-145.

5. Bennassar, 2015, p. 189.

6. MacKay, 2019, pp. 14-15.

7. Los únicos que han analizado El ganso de oro con profundidad son Rinaldo Froldi (1991) y Frederick de Armas (1989; 1994). Froldi (1991, pp. 133-134) resume la falta de estudios críticos.

8. De las 424 obras editadas en Artelope, El ganso de oro es la única que escenifica la peste directamente. Entre las otras 34 comedias que contienen las palabras «peste» o «pestilencia», solo se menciona el contagio de paso, muchas veces en sentido metafórico para hacer una comparación o injuriar: «Sangrienta fiera le nombra; / arsénico y pestilencia / del lugar» (Vega y Carpio, Fuente Ovejuna,
} vv. 1150-1152). 
Si convenimos en la fecha propuesta por Morley y Bruerton para la redacción de El ganso de oro (1588-1595) ${ }^{9}$, resulta que Lope efectivamente anticipa el brote de peste más letal y duradero del siglo, el que se desembarcó del navío Rodamundo en Santander en noviembre de 1596 para hostigar la península ibérica durante seis años sin tregua ${ }^{10}$. Una década antes, durante su exilio en Valencia (1588-1590) Lope había coincidido con otra epidemia de peste, esta vez con su foco en Cataluña ${ }^{11}$. Surgió en Barcelona en 1588: «disparó de su arco una saeta de contagio la Divina Justicia, ofendida de los deméritos de Cataluña, y solo en Barcelona tocadas del veneno murieron treinta mil personas. Cesó el castigo al febrero del año 1590 por la misericordia divina y patrocinio de San Roque» ${ }^{12}$. Aunque la enfermedad no hubiera tocado directamente a Lope, seguramente él habría sido testigo de un aumento de guardas, un mayor escrutinio de viajeros y mercancía, rezos a San Roque («El abogado / que hay mayor contra la peste») ${ }^{13}$ y una desconfianza generalizada mientras la ciudad de Valencia se fortalecía contra el contagio vecino. De cualquier manera, tales reacciones dejaron su huella en El ganso de oro.

La comedia, ubicada en la antigüedad clásica, se compone de una mezcla de estilos y ambientaciones. Con la ayuda de la magia la trama viaja entre la Arcadia y Nápoles, destacándose motivos pastoriles, palatinos y folclóricos y desarrollándose temas del heroísmo, el amor no correspondido y, por supuesto, la peste. En la primera jornada, Lope nos prepara el terreno con escenas de distanciamiento y aislamiento emocional en los jardines idílicos de la Arcadia. Las quejas amorosas llenan los versos y ponen de manifiesto las brechas sentimentales entre los personajes:

Lisena, no seas tan fiera,

que te digan en la cara

que el valle de ti se altera;

que, si ven que tus amores

dan la muerte a dos pastores,

juntaranse contra ti ${ }^{14}$.

Los pastores Pradelo y Ergasto están enamorados de Lisena, quien a su vez está enamorada de Belardo, mientras que él y Silvero están enamorados de Belisa. Evidentemente, el diálogo resultante de tantos enredos sigue las exigencias del género pastoril, pero en estas escenas se percibe sobre todo cierto rechazo de los ideales de la tradición arcádica. De acuerdo con las observaciones de Rinaldo Froldi, los personajes no expresan «[n]ingún deseo de evasión de la realidad a través

9. Morley y Bruerton, 1968, p. 75 .

10. MacKay, 2019, pp. 6-7. En la tragicomedia hagiográfica El rústico del cielo (1605), Lope recuerda esta instancia de peste y la situación privilegiada de Valencia: «Sepan que me ha dicho ya / el Niño Jesús, hermanos, / que la peste no entrará / en su Valencia» (Lope, El rústico del cielo, p. 272).

11. Para más sobre su exilio, ver Rennert, 1904, pp. 37-41.

12. Feliu de la Peña y Farell, Anales de Cataluña, p. 216. Betrán Moya (1994) detalla este brote.

13. Vega y Carpio, Los terceros de San Francisco, vv. 938-940.

14. Vega y Carpio, El ganso de oro, vv. 103-108. Todas las citas de El ganso de oro provienen de la edición digital de Artelope preparada por Gemma Burgos Segarra y en cuya página inicial se puede encontrar un detallado resumen de la obra. 
Por medio de la imagen del hilo cortado, estos versos expresan claramente una ruptura con el mundo arcádico y la promesa de felicidad en los brazos de Belisa. Desamparado y vaciado emocionalmente, Belardo decide seguir con su soledad hasta el fin: «pues quiero caminar más, / que, al fin, llegaré primero / a la muerte que me das» ${ }^{21}$, así provocando otro distanciamiento sentimental y físico que durará hasta el final de la obra.

Cuando Belardo sale desorientado por la otra desembocadura de la cueva, se nota que su viaje a ciegas ha vinculado la Arcadia de la primera jornada con el Nápoles pestilente de la segunda. Si en la Arcadia todo el mundo sufría de enfermedades del amor, en Nápoles se padece una epidemia de peste: «porque toda contagiosa / de pestilencia se abrasa, / desde la más pobre casa / hasta la más poderosa» ${ }^{22}$. Se difunde por «la región del aire contagiosa / que ahora sobre Nápoles se extiende» ${ }^{23}$ y su foco es una tumba, «un cuerpo muerto / cuyo monumento abierto / no da olor sabio ni arabio, / antes fiera y pestilente» ${ }^{24}$.

Hasta aquí, Lope sigue teorías coetáneas. Covarrubias definió la peste como «enfermedad contagiosa, que comúnmente se engendra del aire corrompido» ${ }^{25}$. El doctor y tratadista Juan Jiménez Savariego opinó en 1602 que «del aire como de causa comunísima traen origen todas las enfermedades comunes y pestes $»^{26}$. Alonso de Freylas, otro médico tratadista escribiendo al principio del siglo XVII, ahondó más en las causas: «Otras veces se muda el aire en una calidad putredinosa y pestilente, por estar su substancia mezclada con malos vapores levantados de cosas podridas, y entonces se causan enfermedades comunes y pestilentes, causando un efecto venenoso ${ }^{27}$. En efecto, Lope expone el mismo proceso de corrupción e infección en El ganso de oro: un rebaño paciendo en el campo remueve la tierra y destapa unos huesos, lo cual libera el contagio que desciende sobre la ciudad de Nápoles ${ }^{28}$.

En la comedia, a estas causas naturales se añade un elemento de magia. Los huesos descubiertos pertenecen a un mago difunto, y su desenterramiento activa un encantamiento que trae la pestilencia. Este origen sobrenatural tampoco está lejos de lo que se creía, como apuntó Jiménez Savariego: «Y también por venir por parte donde hay animales ponzoñosos, y por pasar por estancos de agua corrompida, y donde hay corrupción de cuerpos muertos, y puédese añadir a su corrupción por industria y maleficio de hechiceros, inficionando el viento y aire común con su

\footnotetext{
21. Vega y Carpio, El ganso de oro, vv. 895-897.

22. Vega y Carpio, El ganso de oro, vv. 912-915.

23. Vega y Carpio, El ganso de oro, vv. 1073-1074.

24. Vega y Carpio, El ganso de oro, vv. 921-924.

25. Cov., fol. 587 r.

26. Jiménez Savariego, Tratado de peste, fol. 14r.

27. Freylas, Conocimiento, curación y preservación de la peste, fol. 20r. Para más detalles sobre cómo se entendían las causas de la peste, ver Bowers, 2013, pp. 33-35.

28. Lope repite estas creencias en otras obras: «que celos son como peste / que de aire matan la fama» (Los pleitos de Inglaterra, vv. 2301-2302); «Advierto / que ya este difunto huele, / y que conviene sacalle / del aposento a la calle, / por que no dé pestilencia» (La historia de Tobías, vv. 1139-1143).
} 
industria, ayudada del demonio» ${ }^{29}$. Ideas similares se encuentran en El ganso de oro: los huesos del mago, el hechizo y «una sierpe encantada y venenosa» ${ }^{30}$ refuerzan el impacto asombroso de esta pestilencia en los ciudadanos de Nápoles.

Vistos tales casos sobrenaturales, las autoridades médicas recomendaban ante todo allanar el camino a la curación con una purificación espiritual:

Y por esta razón se ha de remitir la verdadera y primera cura desta enfermedad a los teólogos, que son médicos espirituales, para que recetando jarabes, aunque amargos al gusto de nuestra voluntad, purguen y limpien la corrupción de nuestros vicios, y mediante sus consejos saludables, se cure nuestra antigua y contagiosa enfermedad de Adán, y con este medio consigamos la salud del alma y cuerpo ${ }^{31}$.

Estas soluciones radicaban en la importancia del rezo y la confesión de los ciudadanos individuales. A los gobernantes les pertenecía el trabajo de purificar el estado entero, y para los tratadistas, eso significaba reconocer las impurezas y limpiar las ciudades de pecados y pecadores. Los oficiales tenían la responsabilidad de «[v]isitar las casas públicas y echar los vicios y las cárceles limpiarlas de gente inútil y enferma» con la meta de «limpiar toda la república de pecados públicos»32.

Lope pone en marcha semejantes recomendaciones en una escena en la que figura el tribunal político de Nápoles, compuesto por un conde y varios senadores. Buscan una manera de apaciguar a los dioses, sobre todo a la sirena Parténope, patrona de la ciudad: «¿Qué delito cruel, qué enorme vicio / ha hecho esta ciudad, ¡oh! gran Sirena / que hiciste con tu mano su edificio?»33. Reflexionan sobre la utilidad del sacrificio en el templo partenopeo y lamentan la injusta muerte del rey a manos de la enfermedad. Sus cavilaciones son interrumpidas por un grupo que se desfila enfrente de ellos; son «los desterrados / los viciosos, juglares y feroces» ${ }^{34}$. El grupo está formado por dos rufianes, dos rameras, un alcahuete, un gitano y un volteador. El conde explica el razonamiento que da motivo a su exilio:

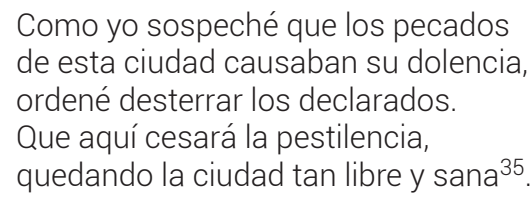

Los desterrados tienen la oportunidad de declararse, y lo que sigue es un diálogo gracioso que, como señala Froldi, tiene el efecto de entrañarles con los espectadores teatrales: «Cada uno de ellos se justifica alegando su inocencia, en un modo que resulta evidente que Lope está de su parte: en el fondo ninguno de ellos es un

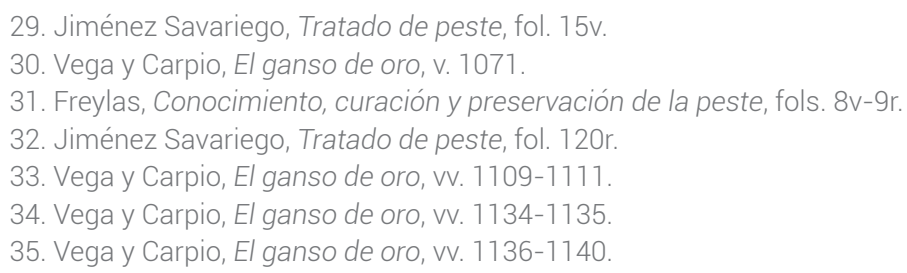


malvado y la medida del destierro en la que cree tanto el conde, acaba por parecer injusta» ${ }^{36}$. Los ruegos de los desterrados no surten efecto, y dejan sus casas, sus vidas y el escenario, obligados al exilio.

En este momento de la obra, el foco de la acción vuelve precipitadamente a la Arcadia, de modo que se vinculan el distanciamiento real del destierro en tiempos de peste y el aislamiento social y emocional en la distopía arcádica. Se aumenta la tensión proveniente de la falta de cercanía emocional, y de nuevo ese sufrimiento se expresa en términos de enfermedad: «Tengo el pecho de sufrir / la llagar antigua del lado, / y de callar y encubrir / carcomido y cancerado» ${ }^{37}$. Buscando el remedio al sufrimiento, los personajes enhebran un diálogo circular y carente de significado que enfatiza la distancia que los separa, una distancia no medida en lo físico sino en la inhabilidad de conectarse el uno con el otro:

$\begin{array}{ll}\text { BELISA } & \text { ¿Adónde mi bien se aleja } \\ \text { SILVERO } & \text { que no he de verme con él? } \\ \text { LISENA } & \text { ¿Así respondes, cruel? } \\ \text { PRADELO } & \text { ¿Así, ingrata, correspondes } \\ & \text { a fe tan pura y fiel? }\end{array}$

En estos versos y los que siguen, los cuatro personajes hablan en una especie de ronda sin respuesta porque sus interlocutores intentan hablar con otra persona. El diálogo así fracturado y fragmentado pone de manifiesto el alto nivel de soledad padecido por los personajes y continúa hasta que Belisa decide exteriorizar lo que siente. Su plan es alejarse de la Arcadia y de sus recuerdos de Belardo; a continuación insiste en irse «[a] buscar / un apartado lugar»39. Aquí Lope emplea el destierro emocional para trazar un paralelo con el destierro físico de Nápoles visto solo unos versos antes. De esa forma, enfatiza el sufrimiento interior mediante una analogía en la que se comparan los efectos de la peste con los del amor no correspondido, dándole al poeta el vehículo perfecto para expresar sentimientos relacionados con la peste sin tener que documentarlos explícitamente ni correr el riesgo de ofender o desagradar a su público.

Como ya hemos mencionado, la peste de Cataluña en 1588-1590 puede haber influido directamente en la redacción de El ganso de oro, y, curiosamente, la decisión de ambientar la comedia en Nápoles puede responder asimismo a factores históricos. La ciudad experimentó brotes de peste en varias ocasiones a lo largo de su historia; ya en la antigüedad el historiador Quintus Lutatius Catulus informó que la tribu que ocupaba la ciudad, por entonces llamada Parténope, pensaba desalojarla, pero una pestilencia les cambió de opinión y decidieron quedarse para edificar Neápolis, o ciudad nueva ${ }^{40}$. En tiempos más cercanos a Lope, la peste volvió a aso-

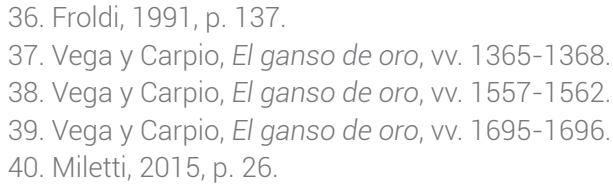


lar la ciudad, y entre sus víctimas figuraron soldados españoles acuartelados allí, tragedia que conmemora Garcilaso de la Vega en su soneto XVI, «Para la sepultura de don Hernando de Guzmán»:

No las francesas armas odiosas,

en contra puestas del airado pecho,

ni en los guardados muros con pertrecho

los tiros y saetas ponzoñosas;

no las escaramuzas peligrosas,

ni aquel fiero ruido contrahecho

de aquel que para Júpiter fue hecho

por manos de Vulcano artificiosas,

pudieron, aunque más yo me ofrecía

a los peligros de la dura guerra,

quitar una hora sola de mi hado;

mas infición de aire en solo un día

me quitó al mundo y me ha en ti sepultado,

Parténope, tan lejos de mi tierra ${ }^{41}$.

Garcilaso le dedica este soneto a su hermano Hernando de Guzmán, quien murió en Nápoles durante este brote de peste en $1528^{42}$. Introduciendo imágenes guerreras, el poeta construye un panegírico marcial que sin embargo se colapsa en el segundo terceto bajo el peso de la palabra «infición». Al yuxtaponer ideas contrarias de tal índole, Garcilaso templa las bravezas de la guerra a la vez que las socava, no blandiendo triunfos de Marte sino llorando una muerte desamparada e indefensa. El soneto termina con una imagen devastadora en su tristeza y soledad, una sepultura efectivamente desterrada de su tierra, su casa y su gente. Del mismo modo que Garcilaso subvierte los códigos literarios de la guerra, en El ganso de oro Lope sigue un proceso paralelo con el cual reescribe el espacio supuestamente idílico de la Arcadia y lo redefine como un jardín estéril que aumenta la desolación y disociación de sus habitantes, forzándoles al exilio.

La separación y el distanciamiento que informan tanto el soneto de Garcilaso como la comedia de Lope tienen sus raíces en la historia legendaria de Nápoles. Entre las veintiséis comedias lopescas ambientadas en Nápoles, El ganso de oro «constituye el más claro homenaje del Fénix a la vieja Parténope a lo largo de toda su carrera dramática» ${ }^{43}$. Tal homenaje consiste en destacar las razones detrás de su fundación en la antigüedad como Parténope «por el nombre de una de las Sirenas que murió en este lugar» ${ }^{44}$. En la Odisea se cuenta que Ulises, ya avisado de

41. Garcilaso de la Vega, Poesías castellanas completas, p. 52.

42. Ramajo Caño, 2011, párrafo 3.

43. Piqueras Flores y Santos de la Morena, 2019, p. 117.

44. Conti, Mitología, p. 537. El Brocense, en sus comentarios a la obra de Garcilaso, explica la historia de la ciudad y destaca la importancia de la sirena y la peste: «Llama la patria de la Sirena a Nápoles porque antes se llamó Parténope, por una de las tres Sirenas, que así se llamaba, cuyo cuerpo allí se halló. Y fundaron aquella ciudad los chalcidicos [calcideos], que son los de Negroponte, y siendo la ciudad asolada por los cumanos, vino sobre ellos gran peste, y por consejo del oráculo de Apolo la tornaron a edificar 
las voces destructoras de las sirenas, mandó que sus compañeros se tapasen los oídos con cera mientras que él iba atado al mástil para escuchar su canto sin peligro. Más tarde él confiesa que las sirenas cantaban «entonando / sus voces muy suaves, de manera / que se me salía el alma de deseo / de oírlas» ${ }^{45}$. En cambio, la sirena Parténope, abatida por no haber podido encantar a Ulises, se tiró al mar, y con el tiempo su cadáver llegó a la ribera de lo que hoy es Nápoles.

Consecuentemente, la base de esa historia y el origen de Nápoles se deriva de una falta de conexión. Ulises se escapa con su vida, afectado por cierta nostalgia de la experiencia, pero las sirenas, derrotadas, se suicidan. Ecos de este mito resuenan en El ganso de oro, sobre todo en la dificultad que tienen los personajes para escucharse y hacer una conexión amorosa, lo cual conlleva continuas amenazas de suicidio por parte de los pastores afligidos. En las dos historias se expresan sentimientos de angustia y soledad, y de esa forma, Lope se aprovecha del fundamento legendario y su separación, distanciamiento y muerte para trazar una analogía con los efectos de la peste en su sociedad contemporánea.

El contagio sobrenatural de El ganso de oro solo puede tener un remedio: una acción heroica con tintes mágicos. Belardo es el elegido para matar la serpiente hechizada y así erradicar los pecados de la ciudad y su castigo de peste ${ }^{46}$. Una vez conseguida su meta, es nombrado rey de Nápoles, y, más pertinente desde nuestro punto de vista, la separación física, social y amatoria entre los personajes empieza a desvanecerse. Los desterrados son los primeros en beneficiarse de este cambio. Celebran con bailes y borracheras su vuelta, entonando su alegría: «Pues ya tenemos licencia / de volver a la ciudad, / iviva su gran majestad / y muera la pestilencia!» ${ }^{47}$. En la última jornada suceden los desenlaces amorosos, antes imposibles en la Arcadia, pero perfectamente habilitados en un Nápoles libre de peste y con todos los personajes principales allí reunidos. Aprendemos la verdad: Belardo y Silvero son hijos del fallecido rey de Nápoles y Belisa es hija de un rey de Atenas. En la resolución de la obra, entonces, Belardo se casa con Belisa, Silvero con la princesa de Roma y Lisena con Pradelo.

En suma, Lope se nutre de varias fuentes para dar profundidad a una historia pastoril, mágica y sobre todo pestilente en El ganso de oro. Con su ambientación en la antigüedad clásica, la comedia elabora conexiones con los mitos de la Arcadia y la sirena Parténope, y estas referencias fomentan analogías con la sociedad na-

\footnotetext{
muy mejor, y a diferencia de la vieja la llamaron Neápolis, que significa nueva ciudad» (Vega, Obras, fol. 102v, nt. 66).

45. Homero, La Ulisea, p. 401.

46. Frederick de Armas (1994), fijándose en el viaje que hace Belardo por la cueva encantada entre la Arcadia y Nápoles, ve una especie de catábasis que responde a la necesidad de la creación de un héroe. Efectivamente, al salir de la cueva, Belardo es nombrado el salvador de Nápoles por el fantasma del mago Dardenio, quien le guía en la búsqueda de la serpiente. Es más, en la tercera jornada, ya exterminada la peste, la sirena Parténope le aparece a Belardo en una visión onírica para darle un amuleto protector en forma de anillo que le salvará de un intento de regicidio, confirmando su estatus heroico y el papel interesado de la sirena en esta historia.

47. Vega y Carpio, El ganso de oro, vv. 1818-1821.
} 
politana apestada que se escenifica en la segunda jornada, todo con una sutileza y suavidad que hace que la comedia agrade a su público. Nuestra crisis sanitaria actual nos ha dado la clave para descifrar los códigos internos de esta infravalorada comedia y entender mejor los temas que propone Lope, sobre todo su insistencia en las ideas de alienación y distanciamiento. Vemos en su fragmentación genérica la imposibilidad de expresar estas emociones sin antes pasar por un filtro alegórico y así poder canalizarlas por una vía que se ajusta a las medidas del arte popular. La pandemia también nos permite simpatizar con los sentimientos y sufrimientos que padecían todos durante semejantes crisis en el Siglo de Oro. De esa forma, El ganso de oro nos ayuda entender mejor nuestro mundo distanciado, fragmentado, dolido, pero no vencido. Podemos esperar, como nos indica la comedia, que una vez salgamos de esta, haya bailes y bodas en los que se escuche decir «que esta impresa / merece bien su angustia, pena y lloro» ${ }^{4}$.

\section{BIBLIOGRAFÍA}

Bennassar, Bartolomé, Valladolid en el Siglo de Oro: una ciudad de Castilla y su entorno agrario en el siglo XVI, Valladolid, MAXTOR, 2015.

Betrán Moya, José Luis, «Medicina popular y peste en la Barcelona de 1589: el proceso de Mestre Bernat Rigaldia», en Muerte, religiosidad y cultura popular: siglos XIII-XVIII, ed. Eliseo Serrano Martín, Zaragoza, Institución «Fernando el Católico», 1994, pp. 279-304.

Bowers, Kristy Wilson, Plague and Public Health in Early Modern Seville, Rochester, University of Rochester Press, 2013.

Clouse, Michele L., Medicine, Government and Public Health in Philip II's Spain: Shared Interests, Competing Authorities, Farmham / Burlington, Ashgate, 2011.

Conti, Natale, Mitología, ed. Rosa María Iglesias Montiel y María Consuelo Álvarez Morán, Murcia, Universidad de Murcia, 1988.

Covarrubias Horozco, Sebastián de, Tesoro de la lengua castellana o española, Madrid, por Luis Sánchez, 1611.

De Armas, Frederick A., «"But Not For Love": Lope's El ganso de oro and As You Like It», en Comedias del Siglo de Oro and Shakespeare, ed. Susan L. Fischer, Lewisburg, Bucknell University Press, 1989, pp. 35-49.

De Armas, Frederick A., «Gyges' Ring: Invisibility in Plato, Tolkien and Lope de Vega», Journal of the Fantastic in the Arts, 3.3/4, 11/12, 1994, pp. 120-138.

Feliu de la Peña y Farell, Narciso, Anales de Cataluña y epílogo breve de los progresos y famosos hechos de la nación catalana, Barcelona, por Juan Pablo Martí, 1709 .

48. Vega y Carpio, El ganso de oro, vv. 2660-2661 
Freylas, Alonso de, Conocimiento, curación y preservación de la peste, Jaén, por Fernando Díaz de Montoya, 1606.

Froldi, Rinaldo, «El ganso de oro de Lope de Vega: un uso temprano de comedia de magia», en Comedias y comediantes: estudios sobre el teatro clásico español, ed. Teresa Ferrer Valls y Manuel V. Diago, Valencia, Universitat de València, 1991, pp. 133-142.

Homero, La Ulisea, trad. Gonzalo Pérez, Venetia, en casa de Francisco Rampazeto, 1562.

Jiménez Savariego, Juan, Tratado de peste, donde se contienen las causas, preservación y cura, Antequera, por Claudio Bolan, 1602.

MacKay, Ruth, Life in a Time of Pestilence: the Great Castilian Plague of 1596-1601, Cambridge, Cambridge University Press, 2019.

Miletti, Lorenzo, «Setting the Agenda: the Image of Classical Naples in Strabo's Geography and Other Ancient Literary Sources», en Remembering Parthenope: the Reception of Classical Naples from Antiquity to the Present, ed. Jessica Hughes y Claudio Buongiovanni, Oxford / New York, Oxford University Press, 2015, pp. 19-38.

Morley, Sylvanus Griswold, y Bruerton, Courtney, Cronología de las comedias de Lope de Vega, trad. María Rosa Cartes, Madrid, Gredos, 1968.

Pérez Moreda, Vicente, «The Plague in Castile at the End of the Sixteenth Century and its Consequences», en The Castilian Crisis of the Seventeenth Century: New Perspectives on the Economic and Social History of Seventeenth-century Spain, ed. I. A. A. Thompson y Bartolomé Yun Casalilla, Cambridge, Cambridge University Press, 1994, pp. 32-59.

Piqueras Flores, Manuel, y Santos de la Morena, Blanca, «"Parténope santa": Nápoles en el teatro de Lope de Vega, un acercamiento por géneros», Anuario Lope de Vega, 25, 2019, pp. 103-121.

Ramajo Caño, Antonio, «"No las francesas armas...": la huella clásica en un epitafio de Garcilaso», Criticón, 113, 2011, pp. 19-33.

Rennert, Hugo Albert, The Life of Lope de Vega (1562-1635), Glasgow, Gowans and Gray, 1904.

Vega, Garcilaso de la, Obras del excelente poeta Garcilaso de la Vega con anotaciones y enmiendas del maestro Francisco Sánchez, ed. Francisco Sánchez de las Brozas, Salamanca, en casa de Lucas de Junta, 1581.

Vega, Garcilaso de la, Poesías castellanas completas, ed. Elias L. Rivers, Madrid, Castalia, 1972.

Vega y Carpio, Lope de, El ganso de oro, ed. digital Gemma Burgos Segarra, Artelope, 2016, en <http://artelope.uv.es/biblioteca/textosAL/AL0646_ElGansoDeOro>. 
Vega y Carpio, Lope de, El rústico del cielo, en Obras de Lope de Vega, V: comedias de vidas de santos y leyendas piadosas; comedias pastoriles, ed. Marcelino Menéndez Pelayo, Madrid, Real Academia Española, 1895, pp. 239-280.

Vega y Carpio, Lope de, Fuente Ovejuna, ed. digital Eva Soler Sasera, Artelope, 2015, en <http://artelope.uv.es/biblioteca/textosAL/AL0640_FuenteOvejuna>.

Vega y Carpio, Lope de, La historia de Tobías, ed. digital Luz Celestina Souto, Artelope, 2014, en <http://artelope.uv.es/biblioteca/textosAL/AL0676_LaHistoriaDeTobias>.

Vega y Carpio, Lope de, Los pleitos de Inglaterra, ed. digital Rosa Durá Celma, Artelope, 2018, en <http://artelope.uv.es/biblioteca/textosAL/AL0803_LosPleitosDelnglaterra>.

Vega y Carpio, Lope de, Los terceros de San Francisco, ed. digital Luis María Romeu Guallart, Artelope, 2014, en <http://artelope.uv.es/biblioteca/textosAL/ AL2006_LosTercerosDeSanFrancisco>. 